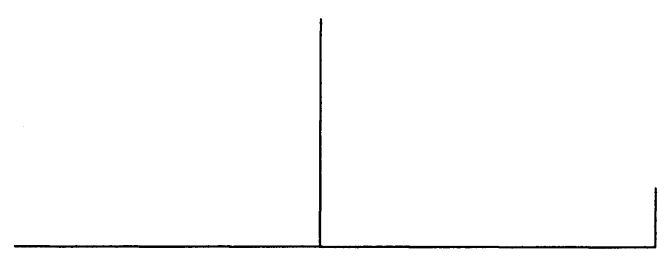

\title{
É possível uma Psicopatologia Fundamental na infância?
}

Maria Cristina Kupfer

$O$ presente artigo examina a possibilidade de inaugurar uma Psicopatologia Fundamental da Infância a partir dos eixos propostos por Costa Pereira e por Berlinck para a constituição de uma nova disciplina, a Psicopatologia Fundamental. Examina-se a história da Psicopatologia na infância, a questão da demanda na análise com crianças e a necessidade de haver, em um trabalho interdisciplinar, a prevalência de uma disciplina sobre as outras. 


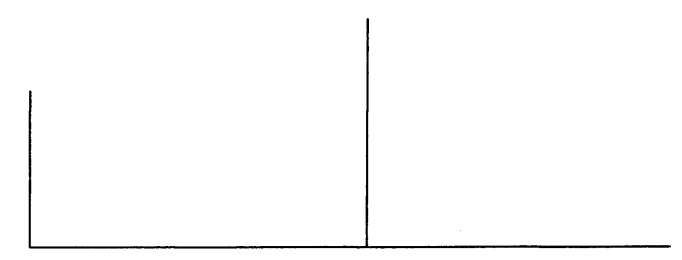

O debate em torno do estabelecimento de uma nova disciplina, a Psicopatologia Fundamental, vem ganhando impulso em um momento especialmente oportuno. O cenário brasileiro, e particularmente o paulista, parece ser aquele em que predominam, com muita força, certas abordagens teóricas e clínicas em psicopatologia geral que não contemplam a implicação do sujeito na fabricação de seu sofrimento psíquico. A psicanálise parece vir perdendo terreno para a Psiquiatria Biológica e até mesmo para a Neurologia. Conta-se, por exemplo, que uma clínica de Neurologia tentou contratar um conhecido psicanalista, pois recebia uma demanda enorme de casos que nada tinham a ver com a Neurologia, e eram claramente situações para a escuta de um psicanalista. Esses pacientes, passados 100 anos da invenção da psicanálise, ainda procuram a Neurologia da qual Freud partiu, e desconhecem a existência da psicanálise!

Assim, se a Psicopatologia Fundamental está interessada em resgatar a dimensão de implicação subjetiva na constituição do sofrimento psíquico, debater essa fundação é crucial para a abordagem do sofrimento psíquico hoje.

No âmbito desse debate, caberia perguntar sobre o lugar que poderia ocupar uma Psicopatologia Fundamental da Infância. Os psicopatólogos fundamentais incluem, sobretudo, o autismo entre os temas sobre os quais deveriam especialmente se debruçar. Esse interesse chama a atenção: por que a predominância dessa patologia infantil? Talvez porque se trate de um dos mais sérios desafios a qualquer tentativa de abordagem terapêutica, seja ela qual for.

Minha proposta de debate, então, é a seguinte: tomarei os eixos em torno dos quais gravita a Psicopatologia Fundamental, tais como foram enunciados por Mário Eduardo Costa Pereira e Manoel Berlinck em seus textos publicados na Revista Latinoamericana de Psicopatologia Fundamental (1998), e os farei trabalhar dentro do campo da Psicopatologia na Infância.

Seguindo a démarche proposta por Costa Pereira de rastrear a história da Psicopatologia Geral, detenhamo-nos um pouco sobre o que seria a história de uma Psicopatologia Geral da Infância.

Um rápido sobrevôo pela história da Psiquiatria Infantil revela duas coisas interessantes.

Em primeiro lugar, observa-se que a Psiquiatria Infantil surgiu como uma Psiquiatria Pedagógica, pelas mãos do médico que a inaugurou, Jean Itard, no início do século XIX. 


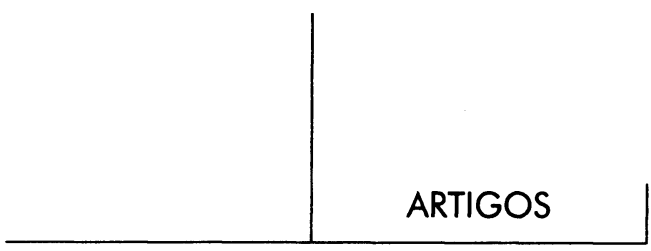

Discípulo de Pinel, para Itard

... a criança encontrada em um bosque da França - Victor - era idiota porque havia sido abandonada, e não o contrário, como diziam seus contemporâneos, para quem Victor havia sido abandonado porque era idiota. "Na horda selvagem mais errante, bem como na naçẳo européia mais civilizada, o homem não é senão aquilo que o fazemos ser: necessariamente criado por seus semelhantes, ele contraiu deles seus hábitos e necessidades; suas idéias não lhe pertencem; ele gozou da mais bela prerrogativa de sua espécie, a suscetibilidade de desenvolver seu entendimento pela força da imitação e pela influência da sociedade", afirmou Itard em 1801 (1994, p. 3). Especialista na educação de surdos-mudos, dispôs-se então a tratar daquela criança, aplicando-lhe o que era chamado na época de tratamento moral. Era moral porque incidia não sobre o corpo, mas sobre as faculdades mentais.

Victor foi apontado como uma criança idiota, uma vez que essa era a grande categoria que servia, na época, para abrigar toda sorte de deficiências mentais. Da perspectiva histórica com a qual estamos instrumentados, porém, Victor seria, provavelmente, diagnosticado como psicótico.

No que consistia esse tratamento? Consistia em educar. Por que e para que educar crianças até então consideradas inaptas para a vida social? Quétel e Postel (1993) mostram, como já foi dito, que estava em jogo uma experiência científica. Pode-se, porém, aventar uma outra hipótese para explicar o furor educandi de Itard. O ideal educativo, no início do século XIX, já estava instalado na forma como hoje o conhecemos. Vinha, desde o século XVII, atribuindo o contorno, a existência e o sentido que o discurso social designa para a criança, como nos mostra Philippe Ariès (1981), referência obrigatória, embora não definitiva, quando se fala de infância. Esse autor demonstra que o novo sentimento de infância gestado a partir do século XVII é totalmente solidário com um novo ideal educativo, construído de modo a atender às exigências político-sociais de uma burguesia nascente. Essa nova articulação entre Infância e Educação é forte ao ponto de levar o psicanalista francês Guy Clastres (1991) a afirmar que o significante 'educação' faz surgir o significante criança, que havia desaparecido. Ou seja, o discurso social moderno cria uma criança cuja consistência está no fato de ela ser submetida a uma educação nova, que implica vigilância, disciplina, segregação. Que implica o surgimento da escola. Nossa criança é, por definição, escolar.

Nos albores da Psiquiatria Infantil (...), assiste-se à tentativa de tratar o jovem Victor de Aveyron ensinando-o a humanizar-se. (Kupfer, 1997)

Esta pequena perspectiva histórica permite entrever, então, que a Psicopatologia Geral da Infância nasce de modo absolutamente solidário a um ideal educativo, e, portanto, normativo.

Ora, uma das tarefas da Psicopatologia Fundamental é, para Costa Pereira, enunciada assim: caberia a ela a perspectiva de "ser responsável por um tra- 


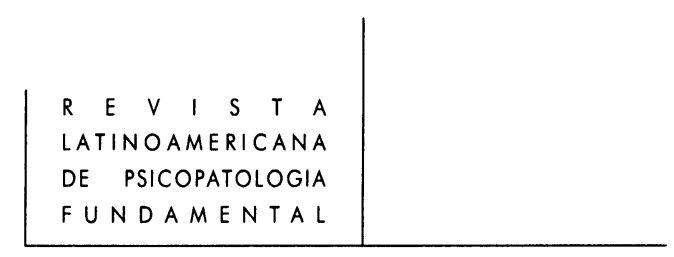

balho de constante delimitação teórica entre as diversas disciplinas envolvidas no campo da Psicopatologia, o que implica uma perspectiva histórica e crítica" (1998, p. 75). Se assim é, então o trabalho a ser assumido por uma possível Psicopatologia Fundamental da Infância será, em decorrência disto, uma delimitação teórica entre pelo menos três disciplinas com ela envolvidas: a Pedagogia que se tornou hegemônica a partir do século XIX, a Sociologia da Infância e a Psiquiatria Infantil, estando esta última comprometida, em seu nascimento, pelas duas anteriores, além de estar com elas confundidas.

A outra interrogação que surge, quando se faz o sobrevôo histórico, é: por que são tão escassas as informações sobre psicopatologia infantil anteriores ao século XIX? Embora haja referências à deficiência mental, chamada de idiotia, trata-se de referências gerais, que incluem os adultos.

Os estudiosos do autismo encontram grande dificuldade em situar casos relatados na Idade Média (Postel e Quétel, 1993). Na Grécia, sabe-se, por outro lado, que a prática da eugenia era freqüente, enquanto na Idade Média ela parecia ocorrer de forma disfarçada (Alexandre-Bidon e Lett, 1997). Outras fontes são a Literatura, que pinta personagens que poderiam ser hoje considerados psicóticos ou autistas, e as lendas, como a das crianças-fada irlandesas, muito parecidas com nossas autistas de hoje. Essas fontes são apontadas por um dos poucos textos existentes a respeito, o de Rosenberg (1994).

Sobre essa, digamos, ausência da psicopatologia infantil na história anterior à Moderna há muito para ser dito, principalmente em torno do fato de que a psicopatologia é sempre uma criação discursiva, mas recortemos um eixo fundamental: tudo parece indicar que a criança só adentra os discursos científicos quando passa a ser digna de nota. E ser digna de nota é ser um sujeito passível de escolarização, de engajamento na força de trabalho e proto-consumidor. E, ao lado disso, de modo muito rudimentar, cujo precursor é Itard, quando passa a ser considerado aproximativamente o que em termos contemporâneos chamamos de "sujeito do inconsciente". "O tratamento moral de Victor, o mais alienado dos idiotas, foi a afirmação da integridade de sua humanidade" (p. 511), afirmam Postel e Quétel, para quem Itard abriu o caminho, retomado mais de um século depois pela psicanálise, para a circunscrição das psicoses infantis e das desarmonias evolutivas.

Assim, se a psiquiatria de Itard é normativa e por isso educativa, fazendo aí nascer uma psicopatologia da infância referida a uma norma, a um ideal de criança normal, ela inaugura, paradoxalmente, uma outra leitura do sujeito infantil, que encontrará naturalmente a sua formulação com Freud.

Pode-se dizer, portanto, que só se iniciaram os tratamentos psíquicos da infância quando se considerou que ali havia um sujeito em sofrimento. 


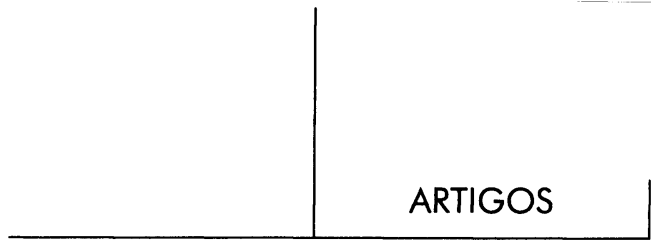

Ora, se assim é, então qual seria a especificidade de uma psicopatologia da infância se, como na geral, estamos diante de um sujeito em sofrimento, cuja idade deixa agora de importar, seja qual for a teoria psicopatológica em jogo? Pois a partir do momento em que se considera que uma criança é sujeito responsável por seus atos, ela deixa de ser uma criança para tornar-se adulto.

A resposta à pergunta pela especificidade pode ser a seguinte: a especificidade de uma Psicopatologia da Infância está em lidar com um sujeito em estado de suspensão.

O problema de uma Psicopatologia Fundamental da Infância será então o de se haver com os problemas éticos, clínicos e epistemológicos, de se ter como objeto psicopatológico um sujeito em estado de suspensão: ou está por advir e é portanto suposto, como é o caso do infans, ou se trata de um sujeito que não adveio, como é o caso de um autista, ou é o caso de um sujeito posto em posição estrutural de permanente vir-a-ser, como é o caso de toda criança (Jerusalinsky, 1989). Estamos, aqui, envolvidos com a segunda tarefa dessa Psicopatologia Fundamental: realizar a teorização do papel dos modelos e paradigmas na constituição tanto do campo da psicopatologia quanto do dispositivo epistemológico de formalização do objeto psicopatológico. Estamos envolvidos principalmente com a segunda parte dessa proposição, ou seja, precisamos dar conta do dispositivo epistemológico de formalização do objeto psicopatológico. Nosso objeto psicopatológico não é portanto a criança, mas o sujeito infantil, que é diferente da dimensão infantil do sujeito, objeto da psicanálise em geral, e será necessário aproximar-se mais desse sujeito peculiaríssimo, que no autismo chega a ser, para Lacan, acéfalo, ou então incorpóreo, e portanto, sem ego. Nosso dispositivo epistemológico de formalização será, então, a pergunta pelo sujeito, sem a qual nada que é da infância poderá ser definido.

Outra decorrência desse estado indefinido de nosso sujeito: se a Psicopatologia Fundamental dirige-se a um sujeito em sofrimento, gerando dele sua capacidade de sabedoria, e extraindo daí a legitimidade ética da intervenção do psicopatólogo fundamental, de onde extrairemos a legitimidade ética de um trabalho com um sujeito ainda por advir, que não demanda nada, que sofre sem o saber, e que não pode, pelo menos em tese, extrair sabedoria de seu ato de falar sobre seu sofrimento a um outro?

Eis porque o trabalho nesse campo precisará incluir pelo menos mais dois sujeitos: os pais. Porque são eles que sofrem pelo filho. A violência de tratar um infans é a mesma que a dos pais que forçam seus filhos a entrar na ordem simbólica, vale dizer, impõem-lhes a castração, sem lhes perguntar se querem. Melhor dizendo: esta é, por excelência, a tarefa dos pais, e dela só nos encarregaremos depois de feitos todos os esforços no sentido de ajudá-los a suportar e a 


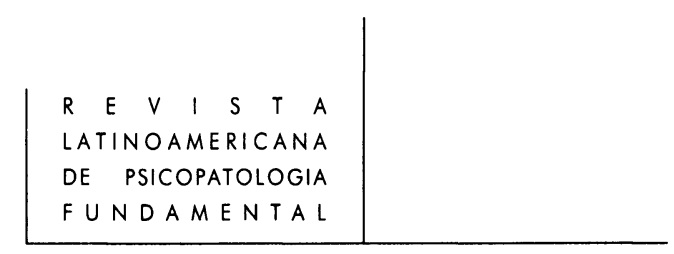

sustentar essa responsabilidade. É com eles que falamos, num trabalho prévio ao analítico, sem deixarmos de supor na criança um sujeito, mas do qual esperaremos o advento de uma demanda para iniciar um trabalho analítico propriamente dito, demanda que virá quando puder ou quiser falar em nome próprio, separado dos pais, como sujeito responsável pelo seu sintoma, e, portanto, a ser analisado como qualquer outro, criança, jovem ou adulto. Por isso também é que Laznik (1991) põe na cena de tratamento do autista a sua mãe, e é pela transferência dessa mulher com o analista que se farão os desdobramentos necessários para uma retomada, ainda que tardia, da especularização. Aqui estaremos então discutindo as bases éticas de um trabalho com a infância.

Falar em bases éticas implica ainda chamar o debate sobre o uso de medicamentos em crianças. Patrícia Gherovic (1997) lembra que o Prozac está sendo largamente utilizado nos EUA. "E, apesar de o uso pediátrico de antidepressivos não ter sido autorizado oficialmente, nos EUA mais de meio milhão de crianças está tomando o famoso medicamento. O New York Times observa que esta medicação é ministrada como uma alternativa às 'custosas psicoterapias tradicionais"” (pp. 15-16). Em entrevista à Veja de 22 de abril de 1998, Hanna Segal alerta para esse uso em crianças. "Na cultura do Prozac não há espaço para a reflexão. No caso de crianças é mais preocupante ainda, por impedir o desenvolvimento normal da criança". (p. 9)

Tomemos agora outro princípio organizador do trabalho de um psicopatólogo fundamental. Este parece estar apoiado no resgate da paixão, no médico que se debruça para ouvir seu paciente, que busca fazê-lo produzir uma experiência, como diz Berlinck. E então temos um problema, quando se trata das "patologiaslimite" na infância: se o autismo está incluído nesse campo, como vamos nos debruçar sobre ele para ouvi-lo falar sobre sua experiência? Sabemos que o preceito fenomenológico de fazer um médico se debruçar sobre o vivido do paciente a ponto de penetrar nele, preceito esse perseguido pela anti-psiquiatria e pela Ambientoterapia, não produziu os frutos esperados, pela impossibilidade de acesso ao autismo a partir de uma experiência tão radicalmente dissemelhante a ele como é a nossa. Parece então que, se quisermos instituir uma Psicopatologia Fundamental de Infância que inclua o autismo, teremos de ampliar o campo de ação do médico em um limite além do sofrimento humano. Supondo que o sofrimento de um autista não está atravessado pelo registro do simbólico, o que não nos autoriza a chamá-lo de sofrimento, e exige que o situemos em um lugar diverso daquele ocupado pelo sofrimento assim chamado neurótico, qualquer psicopatologia que queira inclui-lo deverá supor ou operar com uma categoria como a do Real em Lacan. Ou seja, trata-se de situar essa patologia nas bordas do simbólico, já que há claramente um funcionamento fora dele. Fora dele, mas então onde? Que seja o Real de Lacan, ou então qualquer outra conceituação que dê conta desse "fora". 


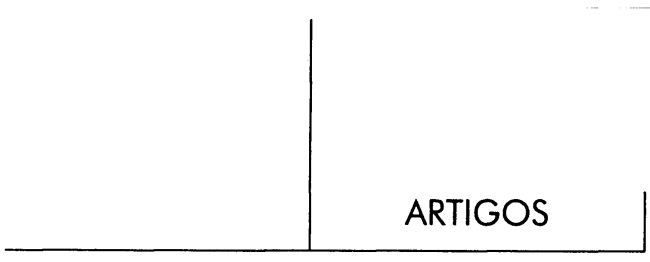

Finalmente, gostaria de discutir o lugar da psicanálise na Psicopatologia Fundamental da Infância.

Berlinck nos lembra que a psicanálise é a casa mais confortável para a Psicopatologia Fundamental, já que nela nasceu a descoberta do inconsciente freudiano como manifestação do pathos. Lembra ainda que a sua babelização impede agora que dela se extraia todo o seu vigor. Costa Pereira acrescenta que a psicanálise corre o risco de um fenomenal isolamento narcísico ao se colocar como único discurso válido, especialmente quando diz ser imaginária a tentativa de compreensão da dor do outro.

Neste ponto, é preciso lembrar então que o alerta da imaginarização na relação analítica não é um reducionismo; ao contrário, abre para outras dimensões da estruturação psíquica, como os registros do Simbólico e do Real, abertura necessária, como já argumentei acima, se quisermos, por exemplo, tratar do autista.

Pede-se também uma relativização dos discursos, para que se revigorem a dialética e o debate com as outras disciplinas. Aqui temos um outro problema. De que posição um psicanalista partirá para o debate, senão daquela construída em sua transferência com ela? Ao relativizar todos os discursos, já que não existem verdades, mas ficções discursivas, não estaríamos em pleno logocentrismo de Derrida? Dizer que tudo pode ser tudo não é o mesmo que dizer que nada pode ser nada? Não seria necessário manter pontos de vista, pontos de ancoragem a partir dos quais sustentar o diálogo com os outros saberes?

Tais questões me foram suscitadas a partir da pesquisa clínica que empreendo atualmente na USP. Trata-se de uma pesquisa interdisciplinar, sobre o diferencial psicose e autismo na infância. É uma pesquisa que vai ao encontro de um dos eixos da Psicopatologia Fundamental, por ser interdisciplinar, eixo já enunciado acima, e que afirma ser ela "responsável por um trabalho de constante delimitação teórica entre as diversas disciplinas envolvidas no campo da psicopatologia, em uma perspectiva histórica e crítica". Vai ao encontro, portanto, porque admite diferentes posições na pólis, para usar os termos de Manoel Berlinck. Supõe que a genética, por exemplo, tenha importantes contribuições a dar ao levar adiante a pesquisa sobre o $X$ frágil. Isto não significa, porém, que o pesquisador psicanalista admita a hipótese causalista da genética. Ou seja, o psicanalista ouve o geneticista, mas mantém sua hipótese clínica e epistemológica a respeito do autismo, colocando-se, portanto, de modo crítico em relação a ela.

Por tudo isso, a pesquisa a que me referia arma um eixo em torno do qual vão girar os dados empíricos gerados pelas outras disciplinas participantes: uma só noção de sujeito. Os participantes da pesquisa são convidados a trazer seus dados colhidos a partir de suas especialidades, mas a discuti-los com os psicanalistas em torno da suposição de um sujeito e de uma certa incidência da 


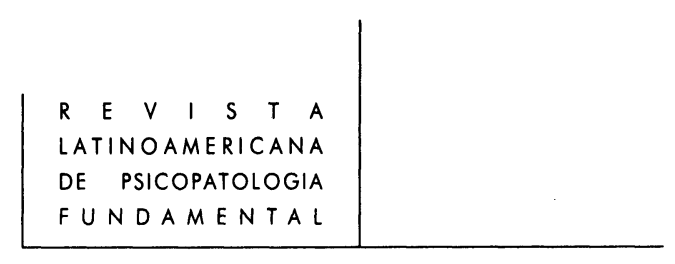

subjetividade proposta pela psicanálise. Aqui se supõe que, se quisermos fazer entrar o sujeito na Psicopatologia, alguma teoria deverá sustentar algum modo de propor a sua definição. Nesse caso, é a psicanálise lacaniana que se encarrega do desenho teórico desse eixo. A psicanálise lacaniana, nesta pesquisa, é prevalente. E parece-me fundamental que assim seja: se, em uma pesquisa diagnóstica interdisciplinar, as diversas disciplinas em torno daquela psicopatologia forem ouvidas sem um eixo comum, o que teremos será um pequeno Frankenstein. Já em uma pesquisa, por exemplo, sobre inclusão escolar do autista, a psicanálise poderá ter algo a dizer, mas não será certamente prevalente.

E como seria exatamente uma pesquisa com o eixo na noção de sujeito em psicanálise?

Por ocasião de um curso sobre a abordagem interdisciplinar dos problemas de desenvolvimento na infância, Jerusalinsky (1996) discutiu as origens da fragmentação interdisciplinar e sua relação com a questão do sujeito:

O nascimento da Ciência Moderna e contemporânea trouxe como conseqüência um deslocamento do estatuto da verdade do sujeito para o objeto (...) Nós nos dirigimos, na busca da verdade, muito mais ao objeto do que ao sujeito (...) Esta suposição de que a verdade opera assim, ou seja, que está absolutamente colada ao objeto (...) permeia a Psicologia, e portanto permeia as diversas disciplinas que se alimentam dela. E uma vez que se supõe que a verdade está no objeto, quanto menor o objeto, maior o nível de certeza que sobre ele se pode atingir. Assim é que surge a fragmentação, que vai dar nas especializações (...) É por isso que o discurso das especialidades faz resistência à interrogação sobre a subjetividade"

Mais, porém, do que se posicionar criticamente em relação ao discurso da Ciência e da Medicina, torna-se necessário levar em conta alguns avanços da área médica. Afinal de contas, todos os profissionais dessa área conhecem os efeitos avassaladores que uma série de síndromes pode ter não apenas sobre o desenvolvimento da criança, mas, igualmente, sobre a constituição do sujeito do inconsciente. Basta lembrar que, até há bem pouco tempo, eram tão comuns os traços autistas em crianças com síndrome de Down que esses traços chegaram a ser considerados como patognomônicos daquela síndrome. Atualmente, alguns psicanalistas consideram que o corpo, em sua dimensão material, não comparece nesses casos como causa, mas como limite, e como provocador de ressonâncias de ordem fantasmática tanto para o sujeito infantil como para seus pais, a ponto de infletir sobre a especularização e ali se produzirem falhas, responsáveis pelo surgimento dos traços autistas.

Levar em consideração a dimensão do corpo em sua materialidade não é, certamente, tarefa fácil para um psicanalista, para quem o corpo é, antes de mais nada, corpo erógeno e construção significante. Mais que isso: não é possível 


\section{ARTIGOS}

pensar em uma soma dos diferentes tipos de diagnóstico realizados por profissionais de diferentes disciplinas.

Mas a interdisciplina, embora trabalhosa, é possível. Apesar do modo como se estabeleceram as especialidades, modo esse que as indispõe contra uma leitura do sujeito, é possível, segundo Jerusalinsky, subverter essa marca de origem histórica das especialidades e propor uma prática interdisciplinar cujo ponto de articulação seja o sujeito posto em posição de ator fundamental.

Veja-se, por exemplo, o dossiê sobre Síndrome de Williams publicado na revista Escritos de la infancia (1995). Ali escreve o neuropediatra da equipe sobre os sinais clínicos mais significativos, como por exemplo algumas características faciais típicas. A psicanalista, diante dessas mesmas características faciais, fará um trabalho de "restituição psíquica aos verdadeiros pais" para essas crianças da "família Williams", que, ao final, acabam por reconhecer nelas próprias os traços que as fazem parecer com seu pai ou sua mãe: aí se recupera uma filiação perdida com a entrada na família Williams. A psicopedagoga pilotará o ultrapassamento de outra característica da síndrome: atraso mental variável. A equipe, que não ignora o saber médico, e o leva em conta, introduz, contudo, a dimensão do sujeito e trabalha na direção de utilizar, pela incitação de fazer falar o sujeito, todo o potencial que sobra à criança dentro dos limites impostos pela síndrome.

Esses são fragmentos de uma pesquisa que, se pode ser situada no campo de uma Psicopatologia Fundamental da Infância, merece, contudo, que dela se discutam alguns elementos em desacordo com aquele campo.

Termino concordando com Costa Pereira quando ele afirma que a consideração, a um só tempo, das várias modelizações em psicopatologia e a incidência da subjetividade no sofrimento psíquico é tarefa difícil e ainda em seus começos. Quando se trata da infância, mais ainda.

\section{Referências Bibliográficas}

(Vários). "Dossiê sobre Síndrome de Williams" (1995). In: Escritos de la infancia. Publicação de F.E.P.I. Fundación para el estudio de los problemas de la infancia. Ano III, n 5, agosto de 1995.

AleXandre-Bidon, D. e LetT, D. (1997). Les enfants au Moyen Age. Paris, Hachette. ARIÈs, Philippe (1981). História social da criança e da família. Rio de Janeiro, Zahar [1973].

BerlincK, M.T. (1998). "Formulando uma Psicopatologia Fundamental". Revista Latinoamericana de Psicopatologia Fundamental. Vol. 1, $\mathrm{n}^{2} 1$, março de 1998.

Clastres, Guy (1991). "A criança no adulto". In: Miller, J. A criança no discurso analítico. Rio de Janeiro, Zahar, pp. 136-140. 


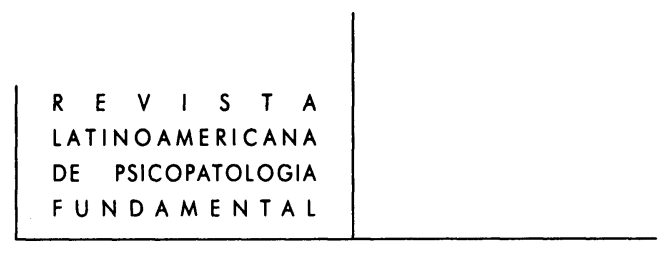

Costa Pereira, M.E. (1998). "Formulando uma Psicopatologia Fundamental". Revista Latinoamericana de Psicopatologia Fundamental. Vol. 1, n 1 , março de 1998.

ItARD, Jean (1994). Victor de l'Aveyron. Paris, Charlemagne, [1801].

Jerusalinsky, A. (1996). "Abordagem interdisciplinar dos problemas de desenvolvimento infantil". Curso de atualização realizado no Instituto de Psicologia da USP, nos dias 04, 05 e 06 de julho de 1996. Transcrição inédita.

KUPFER, M.C.M (1997). “A educação terapêutica”. Estilos da clínica. São Paulo, Pré-Escola Terapêutica Lugar de Vida, do IPUSP. Ano 1, n² 2, 1ํs semestre de 1997.

LAZNIK-PENOT, M-C. (1991). "Il n'y a pas d'absence s'il n'y a de la présence". La psychanalyse de l'enfant. Paris, Editions de l'Association Freudienne, $\mathrm{n}^{2} 10$.

Postel, J. e QuĖtel, C. (org.) (1993). Historia de la psiquiatria. Cidade do México, Fundo de Cultura Econômica.

Rosenberg, R. (1994). "Autismo: histórico e conceito atual”. Separata.

\section{Resumos}

El presente artículo examina la posibilidad de inaugurar una Psicopatología Fundamental de la Infancia a partir de los ejes propuestos por Costa Pereira y Berlinck para la constitución de una nueva disciplina - la Psicopatología Fundamental. Se examinan, em particular, la historia de la Psicopatología en la Infancia, el problema de la demanda de análisis con niños y la necesidad de que, en un trabajo interdisciplinar, prevalezca una disciplina sobre las otras.

Dans ce article, on réfléchit sur la possibilité d'inaugurer une Psychopathologie Fondamentale de l'Enfance, en partant des axes proposés par Costa Pereira e par Berlinck pour la constitution d'une nouvelle discipline, la Psychopathologie Fondamentale. On examine l'histoire de la Psychopathologie de l'Enfant, la question de la demande d'analyse chez les enfants et le besoin, quand il s'agit d'un travail interdisciplinaire, de faire prévaloir une discipline sur les autres.

In this paper, we reflect on the possibility of iniciating a Fundamental Psychopathology for the Infancy, based on the axes that are proposed by Costa Pereira and Berlinck for the constitution of a new discipline, the Fundamental Psychopathology. We analyse the history of the Infantile Psychopathology, the question about who demands a child analysis, and the need, in an interdisciplinary work, of the prevalence of a discipline over the other. 